\title{
El poeta com a personatge literari: Neidhart i Wolfram von Eschenbach a la literatura medieval alemanya
} Victor Millet

\section{La farsa de Hans Sachs}

L'any I 557 el prolífic escriptor alemany Hans Sachs, de Nuremberg, escrigué una farsa de carnaval amb el títol de Neidhart i la violeta (Der Neidhart mit dem veyhel). Es tracta d'una obra breu (508 vv.) en tres escenes. A la primera, el protagonista -Neidhart- troba al prat la primera violeta de l'any, la cobreix amb el barret per protegir-la i corre a avisar la duquessa. Ella organitza ràpidament una sortida amb les seves donzelles, escenifica un ball ritual al voltant de la flor encara coberta pel barret i finalment aixeca el capell. Però enlloc de la flor a sota hi troba una tifa gran i pudent que hi han deixat uns vilatans enemics de

Şie fint Reithart Den feiel.

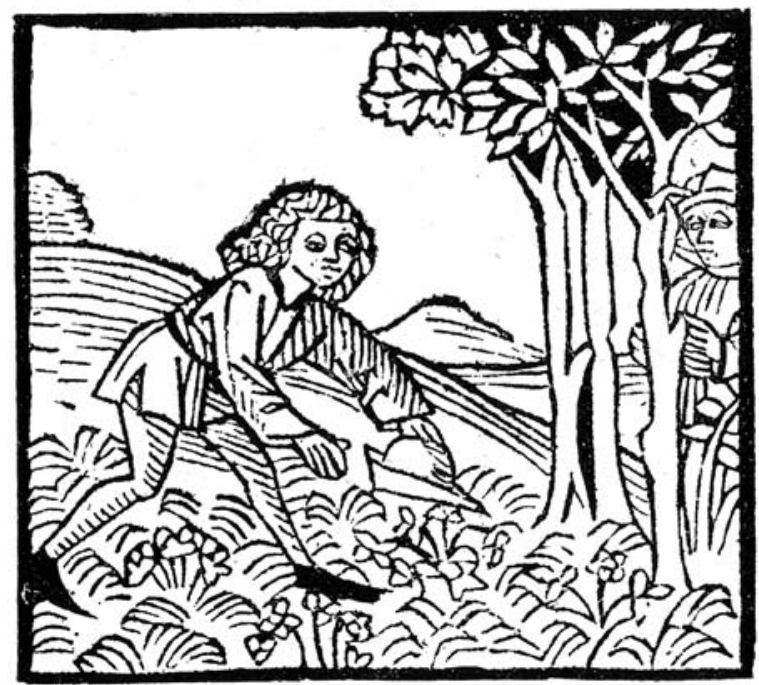

Neidhart cobreix la violeta amb el capell; extret de Bobertag 1884.
Neidhart, que l'han vist tapant la flor i li han volgut fer una mala jugada. A la segona escena Neidhart es venja dels vilatans ferint-los. A la tercera, aquests informen al duc que la dona de Neidhart és molt bonica, sabent que el noble no resistirà la temptació d'inventar un motiu per allotjar-se a la casa del protagonista i intentar seduir la seva esposa. Però Neidhart sospita del duc i s'anticipa, indicant-li que la seva dona és dura d'orella i que se li ha de parlar ben alt; el mateix li diu després a la dona en referència al duc, de manera que, quan es troben, tots dos es criden i no poden dir-se res en secret. El duc torna a casa reconeixent que Neidhart li ha fet la conquesta impossible.

Segons indicació del propi autor al colofó del manuscrit autògraf, la farsa fou acabada el 9 de febrer de 1557 i tenim motius per suposar que va ser representada a Nuremberg durant les festes de carnaval d'aquell mateix any. Hans Sachs ( 1494- I 576) no era cap desconegut a la seva ciutat, perquè a més de mestre sabater fou un personatge actiu a la vida cultural de la ciutat: dirigí l'escola de mestres cantaires (on composà vora de 4000 cançons i 2000 poemes) i escenificà regularment farses de carnaval (n'escrigué 85) i altres obres dramàtiques (en conservem 128). És sens dubte a les farses on aquest autor desenvolupà millor el seu art dramàtic, tot adaptant temes i matèries populars de la seva època. Neidhart i la violeta també és una adaptació, segurament basada en

\footnotetext{
I. El text es pot llegir a Wuttke (1989:237-26I i 358-360); no hi ha traducció castellana o catalana ni per aquest text ni per la majoria dels que comentarem.
} 
Şie Danczt bie herczogin vmb den veiel und bie herczogin Den hut auf.

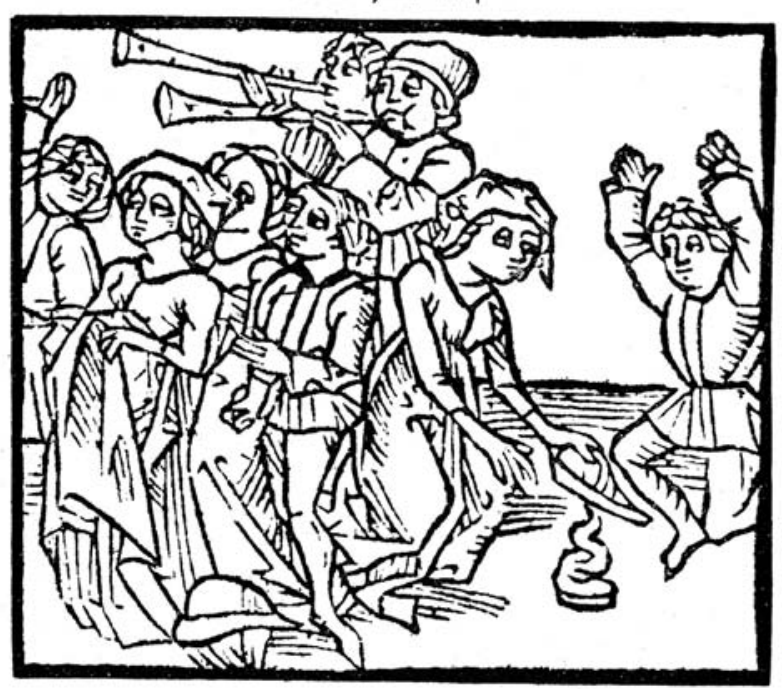

La duquessa descobreix el capell i hi troba la tifa; extret de Bobertag 1884 .

un compendi de sàtires del segle XV que sota el títol Neidhart el Guilla (Neidhart Fuchs) es publicà per primera vegada poc abans del 1500 i es reedità en diverses ocasions fins al 1566. Hans Sachs va aprofitar aquesta compilació per a dues cançons sobre el mateix tema que va escriure entre 1538 i 1539. ${ }^{2}$ De tot això en tornarem a parlar més endavant.

El més curiós, però, és que el personatge de Neidhart que apareix a les obres de Hans Sachs i d'altres és sens dubte la plasmació literària d'un dels principals trobadors alemanys, I'homònim Neidhart. Per tant, ens trobem davant d'un poeta convertit en personatge literari, un fenomen que no és nou, però que tampoc no pot considerar-se habitual a l'època. En les pàgines que seguiran vull fer un breu repàs de l'origen i d'algunes conseqüències d'aquest joc metaliterari tan curiós com poc usual.

\section{Neidhart, el poeta}

Amb el nom de Neidhart coneixem un trobador (o Minnesänger) de la primera meitat del segle XIII. Es tracta d'un poeta probablement d'origen bàvar de qui-com és habitual a la literatura alemanya- no en

2. Les obres de Hans Sachs es troben completes només a l'edició de Keller \& Götze (1870-1908). sabem res. De fet, no estem segurs ni de conèixer el seu nom, perquè només ens ha arribat en dues mencions d'altres autors del segle XIII i per l'epígraf sota el qual els cançoners de finals d'aquella centúria i de principis de la següent ordenaren les seves composicions. Però podria tractar-se d'un nom fictici, perquè l'autor el dóna també al subjecte masculí d'algunes de les seves cançons i no seria el primer cas en què un poeta anònim se l'identifica pel nom d'algun personatge, especialment als cançoners. A més a més, Neidhart també podria ser un antropònim metonímic amb el significat de 'gelós' o 'dimoni', que escauria molt bé al personatge de les seves composicions. En altres casos, sobretot a partir del segle $X V$, el nom apareix complementat amb el gentilici de von Riuwental, que pot ser un nom real, però que significa 'de la vall de les penes' i més aviat sembla un nom figurat. ${ }^{3}$

En certa manera, Neidhart és a la poesia trobadoresca el que Hieronymus Bosch és a la pintura: sota una explosió d'escenes grotesques, la seva temàtica central és la condemna del món, en aquest cas del món de la lírica amorosa. La seva actitud, però, és sempre satírica i mai moralitzant. La major part de les seves composicions poden dividir-se en dos grups: les cançons d'estiu i les d'hivern. Les cançons d'estiu se situen en l'època del bon temps, a espais exteriors i rurals. La protagonista és sempre una dona, generalment una donzella, però a vegades també una vella, desitjosa i fins i tot obsessionada per anar al ball i llançar-se als braços del cavaller de Riuwental, un galant expert en el joc del festeig. Aquestes cançons mostren uns personatges amb un desig desinhibit de reunir-se amb el sexe contrari en el joc, el ball i l'amor, oposant-se amb vehemència contra l'ordre establert, contra les advertències de la mare o contra possibles competidores. Es preveu, però, que la relació serà poc duradora: el desig és carnal, les promeses d'amor són poc versemblants i tampoc no semblen gaire importants. A les cançons d'hivern, que se situen al temps fred i a espais interiors rurals, es distingeixen també dos grups: en unes el protagonista Neidhart es presenta com a galant de cort que festeja -a la manera trobadoresca- les dames de la vila i, si pot, les sedueix sense miraments; a les altres -la majoria- el subjecte entra en competició

3. Trobareu una excel·lent introducció a Schweikle (1990) 
amb els fadrins i encara que les dones se l'escolten una estona, generalment acaben preferint el galanteig més vehement i directe dels vilatans. Aquestes cançons sovint contenen estrofes amb respostes provocadores per part dels rivals, escenes de ball que es converteixen en batalles camuflades, llistes de noms grotescos o burles contra els vilatans. ${ }^{4}$ La vitalitat de les cançons de Neidhart, el caràcter directe de l'erotisme, el ventall de recursos entre la fina ironia i l'obscenitat les converteixen en un gènere atractiu i entretingut, però al rerefons queda clar que mostren un món on l'ordre de les coses s'ha invertit. En aquest sentit, Neidhart és el principal impulsor del discurs literari anticortès.

Encara que els protagonistes siguin gairebé sempre persones llunyanes a la cort i de costums força grollers, s'ha de tenir en compte que la poesia de Neidhart fou escrita per a un públic cortesà i que la seva estratègia consisteix a invertir els termes de l'amor trobadoresc, introduint a la lírica el discurs amorós satíric

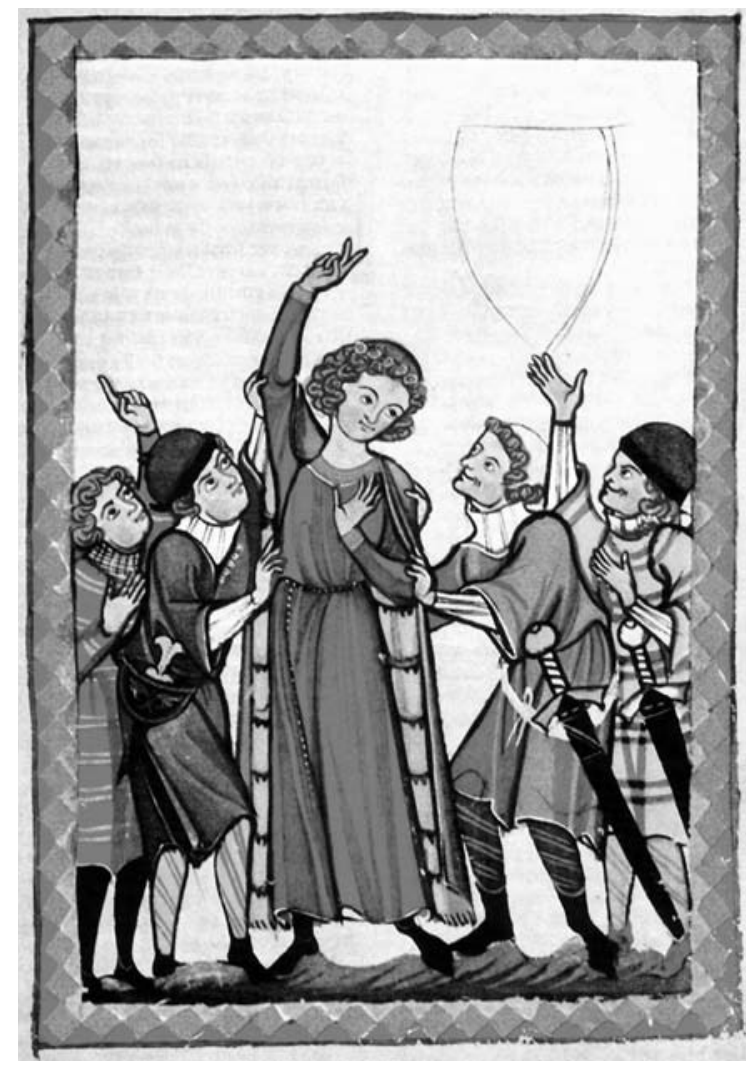

Neidhart (Cançoner Major de Heidelberg, cpg. 848, fol. 273r).

4. Vegeu els textos a la recent edició de Müller, Bennewitz \& Spechtler (2007). que es desenvolupa paral·lelament en altres gèneres, com ara la narrativa breu o l'èpica animal. La seva poesia gaudí d'un èxit continuat a Alemanya, fins i tot creixent. Així ho demostren els cançoners, ja que Neidhart no només figura en els principals reculls del segle XIII i XIV, sinó que és el primer trobador alemany de poesia amorosa a qui es dedica una col·lecció monogràfica. En conservem tres més del segle $X V$, una de les quals (Cançoner Neidhart c, Berlín, Staatsbibliothek, mgf 779) en transcriu gairebé I I 00 estrofes. Cap altre trobador alemany dels segles XII O XIII va despertar tant d'interès dos segles i mig més tard.

A més, Neidhart va crear un estil de cançó que fou imitat ben aviat per altres trobadors, per bé que sempre de manera aîllada. Per això, els principals estudiosos del segle XIX van creure que la gran quantitat de text conservat (unes 1500 estrofes que pertanyen a unes 150 cançons: la seva obra és la més ben documentada de tots els trobadors alemanys) era deguda a l'aparició d'una sèrie d'imitadors anònims que haurien aprofitat l'èxit del mestre per copiar-lo i barrejar les seves obres amb les d'ell. ${ }^{5}$ Començà llavors un debat en torn al corpus de poemes de Neidhart que ha marcat decisivament la recerca. ${ }^{6}$ Encara que avui dia considerem que no hi ha motius filològics clars per dubtar de l'autenticitat de la major part dels textos conservats, també és cert que en un moment o altre es pot haver esmunyit en els plecs manuscrits alguna peça apòcrifa. Demostrar-ho, però, resulta ben difícil.

\section{Neidhart, el personatge}

Un dels motius que més han fet pensar en la creació de material apòcrif és l'aparició, a partir de finals del segle XIII, del que s'ha anomenat la «llegenda» de Neidhart, és a dir la transformació de l'autor en personatge, al voltant del qual s'aglutina un conjunt de relats. Pel que podem saber, el primer pas es donà en una

\footnotetext{
5. Sens dubte, al darrere d'aquesta opinió cal veure-hi una estètica classicista decimonònica, segons la qual el gran poeta no podia ser autor d'una sèrie inacabable de sàtires reiteratives, sinó només d'un nombre selecte de poemes que haurien creat un gènere. Potser també hi va tenir a veure una pressuposició d'origen nacionalista, segons la qual el gran poeta alemany era Walther von der Vogelweide i un satíric no podia superar l'obra del trobador seriós.

6. Vegeu, si no, com redueix el corpus la que era fins ara l'edició estàndard,Wiessner, Fischer \& Sappler (1984).
} 
sèrie de facècies en forma de cançó en les quals el protagonista, anomenat Neidhart, s'enfronta als vilatans de Zeiselmauer (prop de Viena) per fer-ne befa. Coneixem una dotzena d'aquestes cançons narratives, tres d'elles documentades ja en el Cançoner de Weingarten (Stuttgart, Landesbibliothek, HB XIII I), el segon més antic que es conserva (vers 1300), la resta als cançoners del segle $X V$ i sempre sota el nom de l'autor.? Aquestes anècdotes presenten un grup de personatges molt reduït (Neidhart, el vilatà i principal enemic Engelmayer, alguna dona, el duc) i sempre en el mateix espai, però poden ser molt variades. En uns casos els vilatans expulsen Neidhart del ball i ell es venja emborratxant-los o fent-los alguna altra jugada. En d'altres, Neidhart és a la vila disfressat i els en fa alguna: per exemple es presenta com un pobre amb un cabàs de bolets; els vilatans els hi prenen i se'ls mengen, però com que eren dolents els agafa mal de panxa; llavors apareix Neidhart disfressat de curandero i els aplica a tots un ungüent que no fa cap altra cosa que empestar-los amb un tuf insuportable durant sis mesos (L'ungüent / Die Salbe, Beyschlag \& Brunner 1989: 435-44I).

Aquestes facècies ampliaren els elements narratius de les cançons pròpiament trobadoresques. La crítica sempre ha negat que Neidhart en fos el com-

Sie nach volget, wie Reithart bie paumn bejtridg mit ber jalben vnd fi ftundfen bar von, das niemant pei in beleimen mocht.

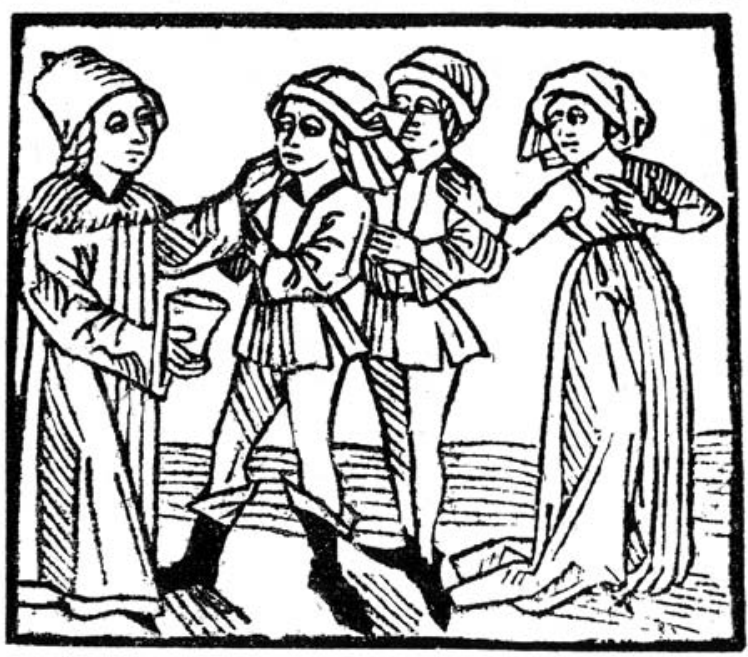

Neidhart aplica l'ungüent als vilatans; extret de Bobertag I884.

7. Els textos han estat editats per Beyschlag \& Brunner (1989) $i$ per Marelli (1999). Vegeu també Simon (1972). 5̧ie wurben fierunozmeinczitg pauren exjhlagen.

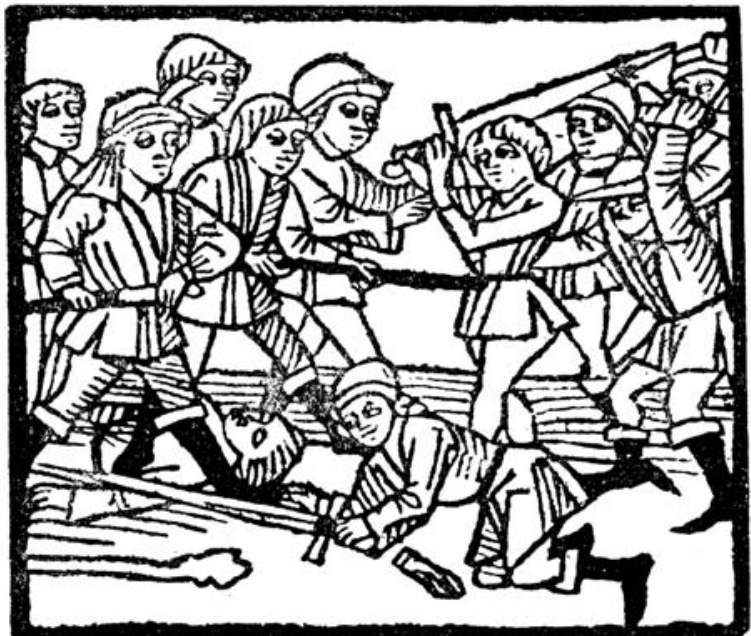

Els vilatans es barallen; extret de Bobertag 1884 .

positor, però el cert és que només en tres casos hi ha motius per afirmar que son apòcrifes. Per tant la idea de convertir el poeta en personatge literari podria perfectament haver provingut del propi autor; al cap i a la fi, també donà el seu nom al subjecte de les cançons trobadoresques. Tornarem a aquest aspecte més endavant.

Al llarg del segle XIV, les facècies de Neidhart i els vilatans semblen haver gaudit de gran èxit, segons que es desprèn de diverses al·lusions d'autors contemporanis. La més important, sens dubte, és una de vers 1400. Entorn aquell canvi de segle, un advocat de Constança anomenat Heinrich Wittenwiler va escriure una novel·la fonamentalment didàctica, però alhora molt grotesca anomenada L'anell (Der Ring). L'obra narra la historia del festeig del pagesot Bertschi Triefnas ('nas mocós') amb la barroera Metzli Rüerenzumpf ('remenatitoles'). La primera part descriu unes extravagants escenes del festeig, la segona relata els preparatius del casament i la bacanal posterior, i la tercera explica com a la festa comencen a anar a bufetades i es declara una guerra entre els dos pobles veïns que en pocs dies implica tota la regió, la noblesa i fins i tot els herois de les novel·les artúriques. Al final, tot s'acaba com el rosari de l'aurora. ${ }^{8}$

A l'inici, però, el jove festejador convoca un torneig perquè ha sentit a dir que això és el que fan els enamorats. Hi participen tots els fadrins de la vila, però

8. Trobareu el text a Wiessner \& Brunner (1991); dóna un estat de la qüestió Riha (1990). 
se'ls presenta un cavaller, Neidhart, que lluita contra els principals i els deixa tots estabornits i malferits. L'escena anuncia el to de la resta de l'obra i sens dubte és una bona manera d'explicar l'origen de l'enfrontament entre Neidhart i els vilatans de què parlen les facècies. Amb aquest passatge, el personatge de Neidhart queda definitivament independitzat de l'autor homònim. Wittenwiler es fa així ressò d'una tendència generalitzada a tota la meitat sud del territori germanòfon, que veu en aquest protagonista una nova figura, molt escaient, per a la composició de relats anecdòtics i grotescs que mostrin la cara inversa de la literatura cortesana.

\section{Altres herois trapelles de la literatura}

La popularitat de les històries al voltant de Neidhart es demostra en el fet que fossin reunides i publicades (amb acompanyament d'algunes cançons) en un llibre imprès a la darrera dècada del segle XV, el ja mencionat Neidhart el Guilla (Neidhart Fuchs). S'hi recullen les dotze facècies, una vintena de cançons d'estiu i d'hivern i una cançó de bacanal del propi autor per formar un cicle de 37 episodis (cadascun amb una xilografia) que ve a ser una mena de biografia rufianesca. El model no era nou, sinó que comptava amb antecedents de força ressonància. El primer fou Mossèn Amís (Der Pfaffe Amis) d'un autor de la primera meitat del segle XIII que, malgrat el volum i la importància de la seva obra, només coneixem pel seu pseudònim: Der Stricker ('el teixidor'). ${ }^{9}$ Es tracta del primer relat extens format per l'agrupament d'un nombre de contes breus amb el mateix protagonista i formant una seqüència biogràfica. No és encara una novel·la picaresca, perquè falten el narrador en primera persona i el particular punt de vista, però s'hi assembla. Algunes de les històries d'aquest llibre circularen per la literatura alemanya fins al segle XVI, per bé que integrades en altres llibres. Un d'ells fou El mossèn de Kalenberg (Der Pfaffe von Kalenberg), un Ilibret publicat a Augsburg el I473, però escrit a Viena per un burgès anomenat Philipp Frankfurter. ${ }^{10} \mathrm{La}$

\footnotetext{
9. Vegeu l'edició de Schilling (1994), amb traducció a l'alemany modern.
}

10. El text fou editat per Bobertag (I884); vegeu també Röcke (1987: I54-212). col·lecció reuneix una sèrie d'històries de les malifetes d'aquest mossèn, que no és sinó un estudiant de teologia que aconsegueix la rectoria de Kalenberg gràcies a una argúcia i que es dedica a mofar-se tant dels parroquians com del propi duc amb trapelleries sofistes o grolleres, a vegades fins i tot escatològiques, que sempre mostren la superioritat intel-lectual del protagonista. El llibre fou un veritable best-seller de l'època, es reedità fins al segle XVII i es traduí a l'anglès $\mathrm{i}$ al neerlandès.

No és aventurat suposar que la composició del Neidhart el Guilla fou influenciada per l'èxit del Mossèn de Kalenberg. En canvi, el títol és una adaptació d'un altre llibret de l'època que tingué molt d'èxit: Reinhart Fuchs, una prosificació de la novel·la sobre la guineu Reinhart escrita al segle XII utilitzant materials del Roman de Renart francès. D'altra banda, l'aparició de Neidhart el Guilla sembla haver estat oportuna també perquè des de mitjan segle XV es començaren a popularitzar les farses de carnaval de temàtica neidhartiana. La primera que se'ns ha conservat és molt breu i fou transcrita vers l'any 1400 a l'àrea del llac de Constança. La segona, en canvi, copiada a finals del segle XV al Tirol, és l'obra dramàtica laica més llarga que es conserva en alemany abans del 1500: conté 2624 versos i implica a seixanta-nou personatges, a més de músics, ballarins i altres col·laboradors. En el mateix còdex hi figura una altra peça, molt més breu i procedent de Nuremberg. De I5 I I és una extensa farsa copiada a Sterzing (Vipitena), al Tirol del sud, i acompanyada d'un rotlle que conté les indicacions escèniques." La darrera és la de Hans Sachs que he comentat al principi. En totes aquestes peces, el nucli de partida el forma l'anècdota de la violeta, a partir de la qual s'afegeixen versions dramàtiques d'altres facècies conegudes o -en algun casdesconegudes.

La importància de la història de Neidhart i la violeta com a peça central d'aquesta producció literària entorn el poeta-personatge queda palesa pels descobriments de frescos en cases senyorials que representen aquesta escena (i alguna altra). La més antiga es troba a Dießenhofen, prop de Schaffhausen i data de 1330, molt abans que tinguem documentades la cançó o la farsa; també en trobem a Winterthur, cap a | 360- I 380, a Viena, cap a |400, i al castell de Trautson, prop del Brenner, a la segona meitat del segle XV.

II. Trobareu els textos a l'edició de Margetts (1982). 
I no es pot oblidar que dos pregons del nord d'Alemanya datats a finals d'aquest segle deploren que la gent il/lustri amb escenes de ball de cançons de Neidhart les seves cases i els seus dormitoris, enlloc de posar-hi representacions dels apòstols (Schweikle 1990: |40-|4|).

\section{Autor, narrador i ficció}

La trajectòria del personatge de Neidhart des de les cançons del poeta homònim de la primera meitat del segle XIII fins a les farses $i$ anècdotes del segle XVI pot qualificar-se sens dubte d'espectacular. L'origen d'aquesta «literaritzaciós del poeta, de la seva transformació en figura literària, cal cercar-lo en la pròpia obra de l'autor. El fenomen és conegut també en l'àmbit romànic: el trobador escriu les seves cançons en primera persona -en els gèneres subjectius, s'enténi manté la idea de la unitat entre el subjecte líric i la seva persona real. Però en la mesura que el poema trobadoresc és fonamentalment fictici -tot i que hi puguin haver al/lusions a la realitat que formen part del joc-, la veu de l'autor en el text es desvincula de la seva realitat extraliterària. D'aquesta manera es crea un personatge-subjecte, una veu poètica que porta el nom de l'autor i sembla que sigui ell, però que no ho és. La diferència rau en el fet que a la poesia alemanya el nivell de creació d'autobiografia fictícia fou molt baix. És per aquest motiu que un gènere com les vidas i razos de la poesia occitana, on algunes dades biogràfiques veritables es barregen amb la ficció creada als propis poemes, seria impensable més enllà del Rin: els poemes no donen prou informació per generar una «biografia». En aquest sentit Neidhart és, juntament amb Walther von der Vogelweide i Wolfram von Eschenbach (d'aquest darrer en parlarem més endavant), un cas excepcional d'elaboració d'elements pseudobiogràfics a la literatura alemanya. L'autobiografia fictícia que va escriure Ulrich von Liechtenstein cap a la meitat del segle XIII, sobre la seva vida al servei de dues senyores diferents, el Servei de dames o Frauendienst (vegeu Thomas 2004), no és imaginable sense el coneixement profund de vidas, razos i altres elements biogràfics dels trobadors occitans i francesos. ${ }^{12}$

12. Vegeu l'edició de Spechtler (1987) i la traducció anglesa de Thomas (2004).
En Neidhart coincideixen dos factors que reforcen el joc amb la identitat de la veu lírica. D'una banda, la creació de cicles de cançons (les d'hivern, les d'estiu i les narratives -encara que no fossin seves, el públic cregué que ho eren-), en les quals es repeteixen les situacions de partida i els personatges implicats, cosa que els independitza del text individual. De l'altra, un tractament peculiar dels rols i les veus en aquests cicles. Així, a les cançons narratives les altres figures es dirigeixen a la veu en primera persona amb el nom de «Neidhart». A les cançons d'hivern, en canvi, el joc es complica, perquè els vilatans dirigeixen les agressions contra una figura que s'anomena «Neidhart» i que òbviament no pertany al seu col·lectiu, però que tampoc no es pot identificar directament amb el subjecte poètic, ja que la primera persona no apareix en la majoria d'aquests textos. A les cançons d'estiu, en canvi, unes vegades la veu sembla relacionar-se d'alguna manera amb un lloc anomenat «Riuwental», mentre que en altres ocasions les noies de la vila parlen de l'objecte del seu desig com un jove «de Riuwental».

Les cançons narratives generalment estan escrites en primera persona, però sovint juguen amb el coneixement de la identitat del subjecte per part dels altres protagonistes de la cançó. Així passa, per exemple, a L'agulla torta (Die krum Nadel, Beyschlag \& Brunner 1989: 342-35 I), quan Neidhart visita el seu enemic Engelmayer disfressat de venedor ambulant. L'home no hi és i, tot xerrant, la seva dona explica al foraster que el marit s'està preparant en secret una jaqueta resistent als cops de puny per poder barallar-se tranquil. Quan arriba Engelmayer, parla en solitari amb el viatjant i li demana noves de Viena. El disfressat li diu que s'hi canta una

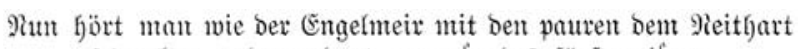

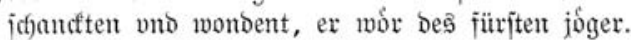

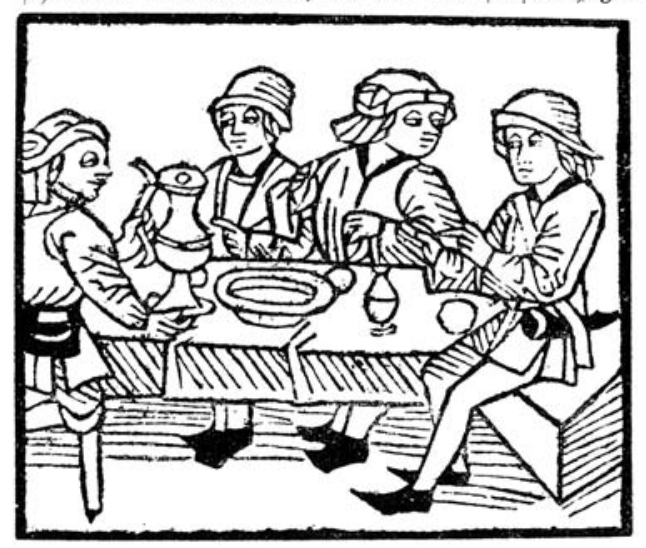

Engelmayer dóna hospitalitat a Neidhart; extret de Bobertag 1884 . 
nova cançó de Neidhart sobre la jaqueta blindada de Engelmayer, i l'improvisa. L'home se l'escolta i es desespera perquè Neidhart coneix els seus secrets fins $i$ tot des de la llunyana capital. De manera similar a d'altres cançons narratives el protagonista s'amaga o s'encobreix davant dels altres personatges del relat, però el públic el coneix. Aquest joc de coneixement i desconeixement de la identitat amb tota certesa fou un factor important en l'èxit d'aquestes peces.

\section{Wolfram i el castell de Wartburg}

La difusió de les històries al voltant de Neidhart i de les seves jugades als vilatans són una mostra clara d'aquesta transformació de l'autor en personatge. Però el cas més emblemàtic és el d'un conglomerat de textos que coneixem pel nom genèric de Disputa a Wartburg (Wartburgkrieg). La Disputa és un conjunt d'estrofes líriques de nombre bastant variable segons els manuscrits (fins a 295 en el testimoni més extens).13 Podem estructurar-lo en tres parts. La primera, que dóna nom al conjunt i es manté més igual en tots el cançoners, descriu una disputa entre sis poetes davant d'un gran noble, el landgrave de Turíngia, per veure qui lloa millor el millor príncep. Es tracta, doncs, del que la poesia occitana anomenaria una tenso entre sis poetes situada en un context que evidencia la relació entre poesia i mecenatge. Suposem que fou composta el tercer quart del segle XIII. Al final del debat només hi ha un perdedor, Heinrich von Ofterdingen, que es permet que sigui substituït per un altre, Klingsor von Ungerlant.

D'aquesta manera s'enllaça amb la segona part, en la qual aquest Klingsor inicia el que els trobadors en dirien un partimen amb Wolfram von Eschenbach: el primer, suposadament un clergue culte i amb coneixement de màgia, planteja unes preguntes i endevinalles en forma d'imatges al·legòriques cada cop mes enrevessades que el segon, que afirma no haver gaudit de formació clerical, respon amb certesa. En el rerefons d'aquest debat hi ha la qüestió de la procedència del saber i de la manera d'obtenir-lo: l'estudi intens del clergue, fins arribar a la màgia i al pacte amb el dimoni, es

13. Podeu trobar el text a Rompelmann (1939), tot i que aquesta edició no dóna una idea de la gran heterogeneïtat de la transmissió textual. Vegeu també el fonamental estudi de Wachinger (1973: I-89).

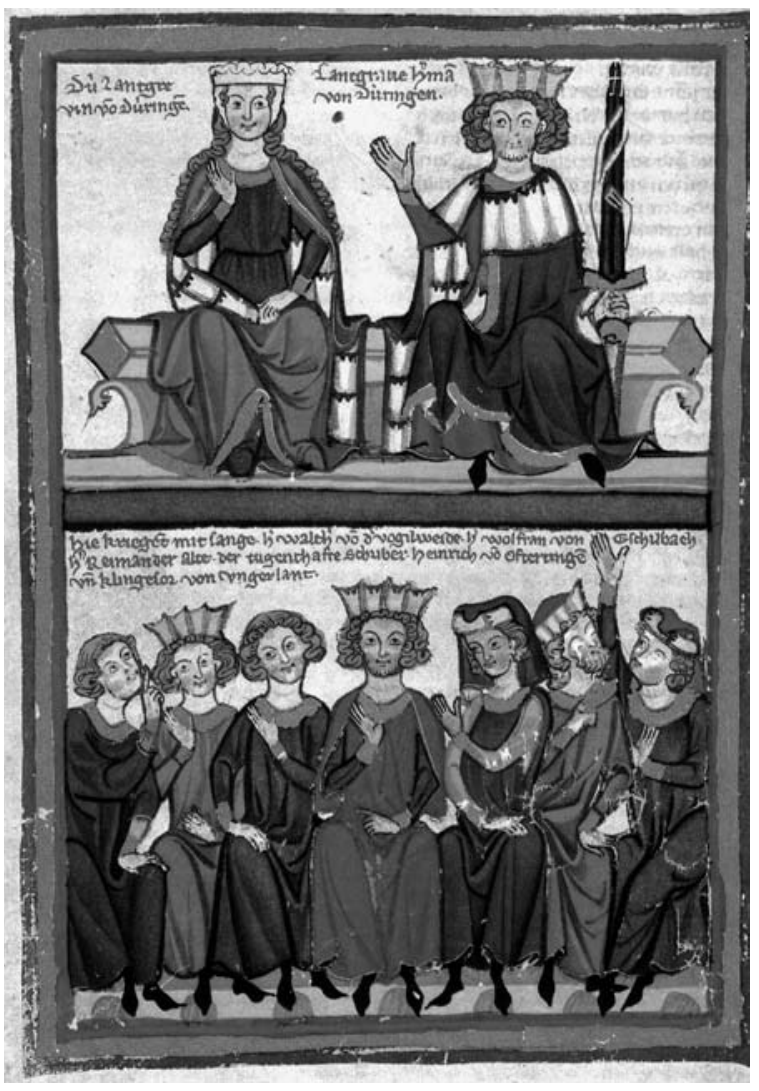

La disputa a Wartburg (Cançoner Major de Heidelberg, cpg. $848 \mathrm{f}$. $219 v)$.

mesura amb el pragmatisme i la fe del llec. La tercera part és la que més varia a tots els manuscrits, i pot constar d'un o diversos conjunts. Un d'ells és una continuació de la segona part, però hi ha també un debat sobre els ordes mendicants, una lloança a dos prínceps morts i alguns parells d'estrofes aillades. En el conjunt dels manuscrits del segle $X V$ s'hi troben mitja dotzena més de grups d'estrofes de temàtica variable, alguns, però, relacionats una altra vegada amb la disputa entre Wolfram i Klingsor, que es converteix així en l'eix central d'aquest corpus.

El debat entre aquests dos poetes forma part de la recepció de Wolfram von Eschenbach a la literatura alemanya del segle XIII. Wolfram no és només un dels grans autors de les dècades daurades al voltant de 1200 (al costat de Hartmann von Aue, Gottfried von Straßburg, Walther von derVogelweide, Neidhart etc.) i autor del Parzival i del Willehalm, dues obres capitals de la literatura medieval, sinó també, juntament amb Neidhart, un dels que gaudirà d'una posteritat més fecunda. Més d'un autor del segle XIII amaga la seva 
identitat darrera el nom de Wolfram i encara que generalment només ho fessin com a joc literari, en un cas es produí una confusió veritable de manera que un monumental text de gairebé vuitanta mil versos fou considerat obra de Wolfram fins al segle XIX.14

Segurament, la transformació de Wolfram von Eschenbach en personatge literari es degué, entre d'altres factors, a la seva creació d'un narrador amb caràcter propi. No hi ha dubte de que Wolfram fou entre els seus coetanis el més atrevit i genial artífex de la figura del narrador fictici. Seva és la famosa frase que declara l'orgull del poeta: «jo sóc Wolfram von Eschenbach i en sé un bon tros de fer cançons» (ich bin Wolfram von Eschenbach / unt kann ein teil mit sange, w. I |4, I2). Però sobretot al llarg de les seves obres narratives, especialment del Parzival, explora en totes les direccions imaginables les possibilitats poètiques de la figura del narrador. Unes vegades es presenta com a omniscient i molt segur d'allò que diu, sobretot als passatges teòrics, però d'altres es mostra poc fiable, fins i tot inoportú amb els seus nombrosos comentaris, especialment quan aquests contradiuen l'acció narrada o confonen el lector precisament quan el relat era més clar. Hi ha algun moment en què el narrador es posa ell mateix en ridícul: per exemple, en una escena del Parzival delata la seva incapacitat de descriure el castell de Schampfanzun perquè no sap aplicar els recursos tòpics de la descripció o, al mateix episodi, arriba tard a la trobada entre els dos protagonistes perquè s'ha entretingut amb tota classe de comentaris al marge i al·lusions literàries, de manera que, quan per fi se centra en el diàleg entre els cavallers, aquests ja han acabat de parlar i s'estan acomiadant (vv. 398,28-403, I0). En altres moments ressalta també la distància entre el narrador i la història, convertint-lo en un personatge més de la novel·la. Així arriba a negar-li el relat al públic quan diu «Que com va ser la festa? / Pregunteu-li-ho a qui hi hagi rebut presents!» (Wie diu hôchzît ergienc, / des fragt den der dâ gâbe enpfienc, vv. 397,7 s.), deixa en les seves mans la veritat del conte tot dient «Si ho ordeneu, serà veritat» (gebietet ir, sô ist ez wâr, w. 59,27) o fins i tot inverteix els termes habituals de garantia de credibilitat, convertint el públic en garant de la veritat del conte: «M'han dit, i jo també ho dic / sota jurament de cada un de vosaltres, / ... / de manera que, si jo enganyo algú / vosaltres ho estareu fent amb mi» (Man sagte mir, diz sag

14. Vegeu un resum de la recepció de Wolfram von Eschenbach en la literatura alemanya fins al segle XVI a Millet (2000). ouch ich / ûfiuwer iesliches eit, / ... / sol ich des iemen triegen, / sô müezt ir mit mir liegen, w. 238,8- I2). ${ }^{15}$

Amb Wolfram la figura del narrador assoleix un grau d'independència respecte de l'autor i de la història com no es repetirà en molt de temps. Les qualitats i defectes del narrador que es fan palesos, les dades pseudobiogràfiques que es revelen i les seves intervencions en forma de comentaris incessants contribueixen a convertir-lo en una instància amb aparent personalitat pròpia. Aquest és el Wolfram que coneix la literatura posterior i que reapareix com a personatge a la Disputa de Wartburg. El fet més revelador és el suposat analfabetisme de l'autor, que es basa en un passatge del Parzival on l'autor sembla afirmar que no sap llegir: «No ho tingueu per un llibre. / Jo no en sé de lletres / i ja hi ha qui es basa en elles. / Però aquesta aventura / va sense la guia dels llibres») (dern zels ze keinem buoche. / ine kan decheinen buochstap. I dâ nement genuoge ir urhap: I disiu âventiure / vert âne der buoche stiure, w. I I5,2630). La crítica ha demostrat que no es tracta de cap revelació autobiogràfica, sinó d'un intent de donar una legitimació a una història que no parteixi de la cultura clerical. Donat que el personatge de Wolfram es composà a partir de les dades pseudobiogràfiques que contenien els textos, l'autor va passar a ser d'aquesta manera el representant més insigne d'un corrent que defensava el saber laic.

A finals del segle XIII, el dominicà Dietrich von Apolda va incloure a la seva Vida de Santa Elisabeth de Turíngia llatina una breu referència al mencionat debat entre poetes. Una nit, diu, Klingsor era al castell de Wartburg per la disputa, mirà els estels i anuncià el naixement d'Elisabeth a Hongria, el seu matrimoni amb el príncep de Turíngia i la seva santificació. ${ }^{16}$ Aquest passatge, que només pretén introduir un senyal celestial amb ocasió del naixement de la santa, va donar -probablement sense voler-ho- una localització i una data per a la celebració de la disputa poètica que la historiografia local de la primera meitat del segle XIV aprofità de bon grat per convertir la situació fictícia del debat en un fet històric situat al castell Wartburg, prop d'Eisenach, el I207. En

\footnotetext{
15. El Parzival es pot llegir en la traducció de Regales (200I), encara que hagi estat incapaç de reproduir els innombrables canvis d'estil de l'autor, cosa que dificulta molt la comprensió del text. És molt millor la traducció anglesa de Hatto (1980). Trobareu el text original, amb traducció a l'alemany modern, a Schirok (1998) i a Nellmann (1994).
}

16. Els textos $\mathrm{i}$ les dades següents es troben ara a l'estudi de Wachinger (2004). 


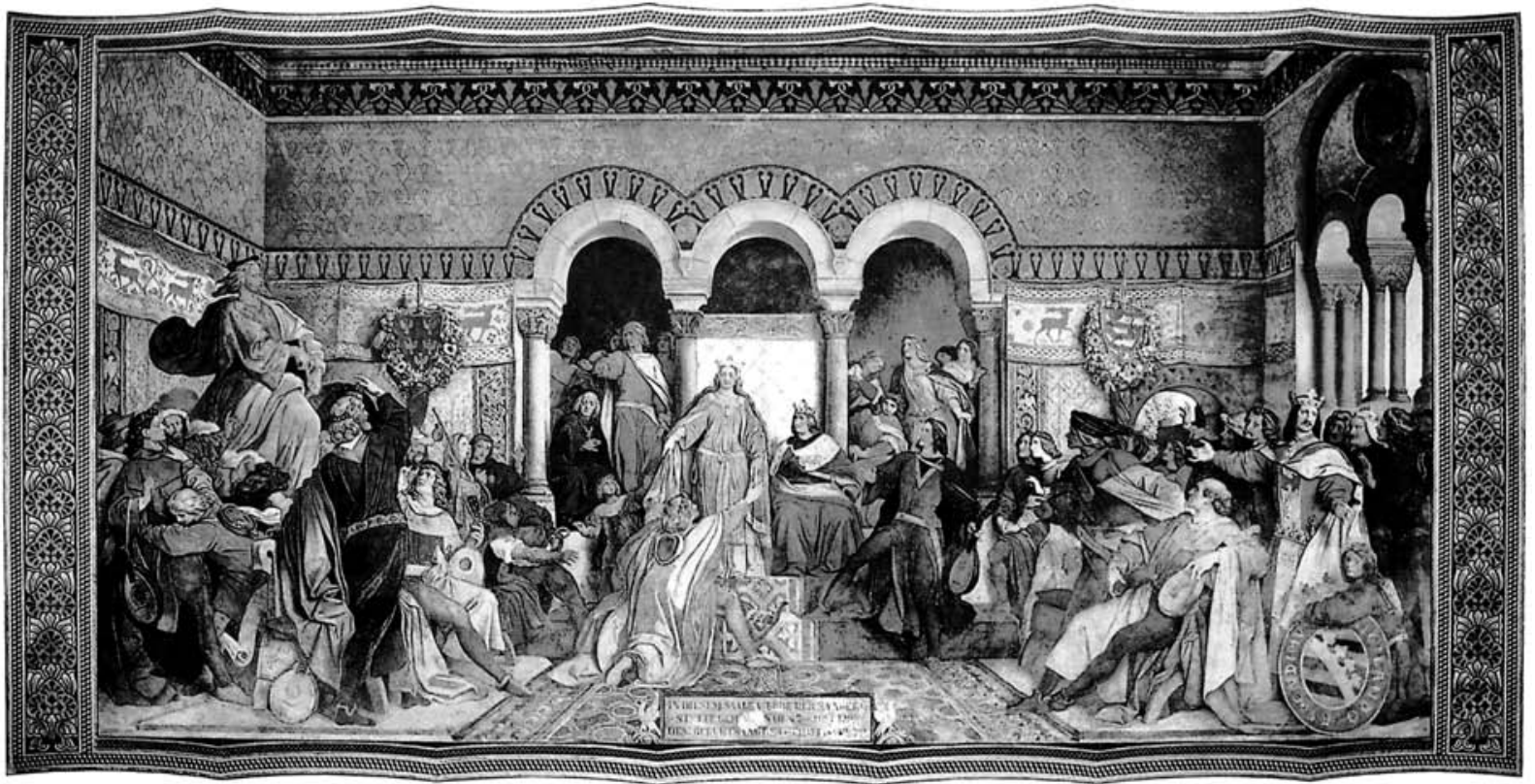

Moritz von Schwind, Der Sängerkrieg (fresc al castell de Wartburg, 1854).

el context de la recuperació d'aquest castell a principis del segle XIX es consolidà la idea que el saló principal va ser l'escenari de la trobada entre poetes més espectacular que es recorda. Durant la restauració feta a partir de 1838, el pintor Moritz von Schwind rebé l'encàrrec de pintar-hi un fresc que representés l'escena. Encara avui dia els turistes que visiten el castell marxen amb l'idea d'haver estat al saló on va tenir lloc aquest famós debat del qual mai no havien sentit a parlar.

\section{El personatge com a poeta}

Neidhart i Wolfram no són els únics autors convertits en personatges en la literatura alemanya. De fet, la resta de contrincants a la Disputa de Wartburg són també personatges d'aquesta ficció. Però els seus casos són diferents; d'una banda hi ha Walther von derVogelweide, Reinmar von Zweter i l'anomenat Escrivà Virtuós (DerTugenthafte Schreiber), que són (sobretot els dos primers) autors fonamentals d'aquesta poesia que a Alemanya anomenem «proverbial» i que constitueix un gènere clarament diferenciable de la poesia amorosa (més que no pas a la tradició romànica, on les relacions formals i codicològiques entre el sirventes i la canso són més estretes). ${ }^{17}$ Per tant, la pre-

17. Com a introducció a aquest gènere poètic cal consultar Tervooren (1995). sència en aquest conjunt de poemes de debat d'aquests autors és més lògica i sobta menys, i el seu paper és molt menys destacat. D'altra banda, tenim Heinrich von Ofterdingen un nom de trobador que, pel que sabem, és fictici: no consta enlloc, ni a la documentació històrica, ni als textos literaris, cap persona amb aquest nom. ${ }^{18}$ No sabem si la invenció és deguda a la voluntat de no convertir cap trobador real en perdedor del debat o si s'hi amaguen al/lusions que ja no podem entendre. En tot cas, l'autor d'aquesta primera part de la Disputa hauria pogut recórrer al mateix procediment que va fer servir en el cas del darrer trobador de la disputa, el clergue Klingsor.

El contrincant de Wolfram és, de fet, un personatge extret del Parzival. En una de les aventures de Gawan, aquest cavaller arriba a un castell que fou construït per un mag anomenat Clinschor. ${ }^{19}$ Fidel al seu costum de no deixar mai de narrar cap història, per marginal que sigui, Wolfram explica que aquest home era un clergue castrat per adulteri que va anar a Pèrsia a estudiar màgia. Des de llavors no deixà de molestar i robar a la gent noble. Així va aconseguir també el castell, on hi col·locà algunes meravelles, però on també mantingué raptades un bon nombre de dones, entre les que cal destacar la vídua d'Uterpandragon i la mare i la germana de Gawan.

18. Cosa que no va privar Novalis d'escriure la seva famosa novel la Heinrich von Ofterdingen.

19. Per situar els lectors que només coneguin Li contes du graal. 
Aquest personatge és, doncs, el que s'utilitza a la segona part de la Disputa com a contrincant de Wolfram. De fet, en la mesura en què el narrador -especialment el del Parzival- es converteix en personatge de ficció, no hi ha diferència entre un cas o l'altre, entre utilitzar el nom d'un autor veritable (Wolfram) o el d'un inventat (Klingsor) com a suposats autors d'un conjunt d'estrofes. El més curiós, però, és que el Cançoner Major de Heidelberg (Heidelberg, Universitätsbibliothek, cpg 848, primer terç del segle XIV), que ordena tots els seus textos per corpus d'autors i que és el primer en transmetre la Disputa, copia aquest conglomerat de textos sota el nom de Klingsor d'Hongria (Klingesor von Vngerlant). Com que el cançoner és una recopilació d'obres d'autors de veritat, Klingsor ascendeix aquí a la categoria de poeta històric. La miniatura que precedeix el text i figura sota el nom de Klingsor mostra a la part inferior els set contrincants (sis més Klingsor) i a la part superior el landgrave de Turíngia i la seva esposa presidint l'escena (vegeu-la a la p. 13). D'això se'n dedueix que qui va fer o encarregar el manuscrit entenia ja la Disputa com un text que recollia una escena històrica i creia que tots els personatges implicats eren reals. La miniatura és, doncs, un reflex del procés d'historització de la Disputa. En obres posteriors sobre l'art poètica, Klingsor figurarà sempre entre els venerables fundadors del gènere.

El Cançoner Major de Heidelberg inclou un altre cas de transformació de personatge literari en autor, i en una posició molt destacada. El còdex ordena els corpus d'autors per categoria social (almenys fins al punt on es copien els autors d'extracció nobiliària), motiu pel qual l'emperador Enric VI figura en primer lloc, seguit del rei Conrad el Jove. Però en tercer lloc apareixen el «rei Tyro d'Escòcia i el seu fill Fridebrand» (Künig Tyro von Schotten vnd Fridebrant sin sun). Els noms provenen del text mateix que presideixen, el qual -curiosament- no pertany al gènere de la poesia amorosa, sinó que és un fragment d'un diàleg didàctic entre pare i fill. Suposem que aquesta obra (que només conservem en aquest manuscrit) fou escrita cap a mitjan del segle XIII, però el seu autor ens és tan desconegut com ho devia ser per als compiladors del cançoner. En aquest cas, doncs, sembla que la idea de convertir els personatges en autors no va provenir de cap joc literari. Però crida l'atenció que als primers dos llibres del Parzival de Wolfram hi apareix un Fri-

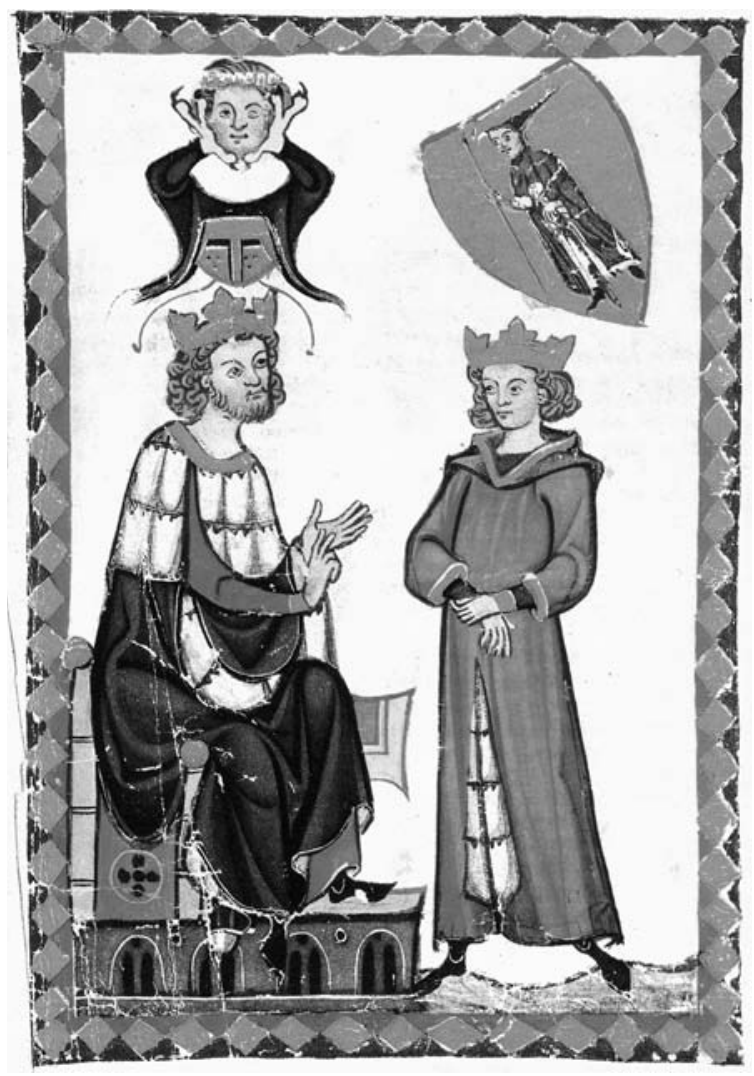

El rei Tyro d'Escòcia i el seu fill Fridebrand (Cançoner Major de Heidelberg, cpg 848, f. 8r).

debrand que és rei d'Escòcia. Segurament, l'autor d'aquesta obra didàctica aprofità el nom del personatge d'una obra famosa com a reclam per al seu text. I no es pot excloure que el fet que el públic i l'entorn dels creadors del cançoner reconeguessin en Fridebrand un personatge del Parzival facilités la seva transformació en poeta històric.

La farsa de Hans Sachs no és, per tant, un cas aillat, sinó el final d'un corrent de recepció dels clàssics que els convertí en personatges de literatura (i que també transformà en històrics alguns personatges ficticis). Les conseqüències d'aquest procés, que mostra el dinamisme del sistema literari alemany, arriben fins al segle XIX, quan el coneixement popular dels autors medievals recentment descoberts fou influenciat -per una manca de contacte amb el món acadèmic- per aquestes llegendes teixides al voltant d'alguns autors clàssics. Potser el cas més conegut fou el de Tannhäuser, que va obtenir ressò internacional gràcies a l'òpera de Wagner. Però és també un cas molt particular que pot quedar per a una altra ocasió. 


\section{Bibliografia}

BeYsChLAG, Siegfried i Horst BrunNeR (eds.), 1989: Herr Neidhart diesen Reihen sang. Die Texte und Melodien der Neidhartlieder mit Übersetzungen und Kommentaren, Göppingen: Kümmerle.

BOBERTAG, Felix (ed.), I 884: Narrenbuch. Der Pfarrer von Kalenberg. Peter Leu. Neithart Fuchs. Salomon und Markolf. Bruder Rausch, Berlín: Spemann (reimpr. Darmstadt: Wissenschaftliche Buchgesellschaft, 1964).

HatTo, Arthur T. (ed.), 1980: Wolfram von Eschenbach: Parzival, Londres: Penguin.

von Keller, Adelbert i Edmund Götze (eds.), 1870-1908: Hans Sachs: Werke,Tübingen: Litterarischer Verein in Stuttgart (reimpr. Hildesheim: Olms, 1964).

MARelLI, Paolo, 1999: Gli «Schwanklieder» nella tradizione neidhartiana. Trascrizione dai manoscritti f/c/pr, traduzione, commento. Con edizione critica del «Bremenschwank», Göppingen: Kümmerle.

MARGETTS, John (ed.), 1982: Neidhartspiele, Graz: Akademische Druck- und Verlagsanstalt.

Millet,Victor, 2000: «Wolfram contra Parzival. La recepción del Parzival y de Wolfram von Eschenbach en la literatura alemana (siglos XIII-XVII)», Parzival. Reescritura y transformación, ed. Berta Raposo, València: Universitat, I57-I83.
MülleR, Ulrich, Ingrid BENNEWITZ i Franz Viktor SPECHTLER (eds.), 2007: Neidhart-Lieder. Texte und Melodien sämtlicher Handschriften und rucke, Berlín: de Gruyter.

NellmanN, Eberhard (ed.), 1994: Wolfram von Eschenbach, Parzival. Nach der Ausgabe von Karl Lachmann, revidiert und kommentiert von Eberhard Nellmann. Übertragen von Dieter Kühn, Frankfurt: Deutscher Klassiker Verlag.

Regales, Antonio (ed.), 200I: Wolfram von Eschenbach: Parzival, Madrid: Siruela.

RIHA, Ortrun, 1990: Die Forschung zu Heinrich Wittenwilers «Ring» I85 I1988,Würzburg: Königshausen \& Neumann.

RÖCKE,Werner, 1987: Die Freude am Bösen. Studien zu einer Poetik des deutschen Schwankromans im Spätmittelalter, Munic: Fink.

ROMPELMANN, Tom Albert (ed.), 1939: DerWartburgkrieg, kritisch herausgegeben, Amsterdam: $\mathrm{H}$. J. Paris.

SCHILLING, Michael (ed.), 1994: Der Stricker: Der Pfaffe Amis, nach der Heidelberger Handschrift cpg 34I, Stuttgart: Reclam

SCHIROK, Bernd (ed.), 1998: Wolfram von Eschenbach: Parzival. Berlín: de Gruyter.

SCHWEIKLE, Günther, 1990: Neidhart, Stuttgart: Metzler
SIMON, Eckehard, 1972: «Neidharte and Neidhartianer. Notes on the History of a Song Corpus», Beiträge zur Geschichte der deutschen Sprache und Literatur (Tübingen), 94, I53-I97.

SPECHTLER, Franz Viktor (ed.), 1987: Ulrich von Liechtenstein: Frauendienst, Göppingen: Kümmerle.

TERVOOREN, Helmut, I995: Sangspruchdichtung, Stuttgart: Metzler.

THOMAS, John W. (ed.), 2004: Ulrich von Liechtenstein's "Service of ladies»:An Autobiography, WoodbridgeRochester: Boydell.

WACHINGER, Burghart, 1973: Sängerkrieg. Untersuchungen zur Spruchdichtung des 13. Jahrhunderts, Munic: Beck.

WACHINGER, Burghart, 2004: Der Sängerstreit auf der Wartburg. Von der Manessischen Handschrift bis zu Moritz von Schwind, Berlín: de Gruyter.

Wiessner, Edmund, Hanns Fischer i Paul SAPPLER (eds.), I 984: Die Lieder Neidharts, Tübingen: Niemeyer.

WIESSNER, Edmund i Horst Brunner (eds.), 1991: Der Ring, Stuttgart: Reclam.

WUTTKE, Dieter (ed.), I 989: Fastnachtspiele des 15. und 16. Jahrhunderts, Stuttgart: Reclam. 